This is a prepublication version of the following:

Vaughan, L., Arbaci, S., 2011. The Challenges of Understanding Urban Segregation. Built Environment 37 (2), 128-138. 


\title{
The Challenges of Understanding Urban Segregation
}

\author{
LAURA VAUGHAN and SONIA ARBACI
}

Despite a century of research into urban segregation, patterns of immigrant settlement are still insufficiently understood. This topical issue requires radical thinking, particularly as it is currently dealt with by a range of disciplines, each of which tends to rely on its own research paradigms. This paper reviews some of the key challenges of studying the subject, starting with the concept of segregation being more complex than the simplistic label of 'ghetto' might suggest. The paper also shows how approaches to the challenges of understanding urban segregation differ according to its given geographical context and disciplinary approach. It shows that segregation is a multi-dimensional process, requiring a multidisciplinary approach. The paper concludes that research into segregation needs to address the fact that it is an inherently complex and fundamentally spatial phenomenon.

\section{Introduction: Outsiders in Society and Space?}

Space is an integral part of the outsider problem. The way in which space is organised affects the perception of the 'other', either as foreign and threatening or as simply different.

Sibley, 1992, p. 116

Spatial segregation is, historically, an undeniable urban reality. Cities by their nature bring together disparate people and activities, yet every period brings a new phase of discourse about the supposedly problematic nature of spatial/social division. Despite being a perpetual phenomenon, segregation as a central theoretical argument, oscillates between active and quiet periods, recurrently coming back to the academic and political agenda in the wake of significant politico-economic and urban change. For example, a recent resurgence of academic interest has come about as a result of discussions on the apparent impact of economic globalization on urban spatial reorganization, allegedly requiring a 'new' spatial order (Marcuse and Van Kempen, 2002). For the general public, segregation - and its more pejorative conception as a problem of 'ghettoization' - are the sort of timeless issue which rises to the top of the agenda in the aftermath of alarming events, such as the French suburban riots of 2005 and 2007 or the earlier disturbances in northern English cities. The impact of mass media coverage of such events is further reinforced when inflammatory language is used to describe them. Phrases such as 'sleepwalking to segregation' resonate years after they have been refuted (Phillips et al., 2007).

The conception of segregation as an urban problem can be dated back to the 1920s Chicago School of Sociology, where Robert Park (1926) conceived of three stages of immigrant settlement, starting with living in an inner-city 'ghetto', with upward mobility towards the ultimate goal of dispersal. This conception has been criticized for its oversimplification of the migration and settlement process. Peach (2005, p.48) has pointed out that one of the key problems with this notion is that it confuses the temporary - and 
temporal - nature of most minority settlements with the permanent and highly problematic nature of the Black American enforced concentration in economically deprived settlements:

The failure to distinguish between the ghetto and the enclave has had a pernicious effect on the understanding of ethnic areas in American cities ... it has conceptualized the ghetto as a temporary phenomenon. In reality, the [black] ghetto has become permanent. Economic differences are not unimportant, but they do not explain black segregation... In reality for those groups who choose it and for whom it is not enforced, concentration has many benefits. However, we need to be able to recognize the difference between the chosen enclave and the enforced ghetto. (Our emphasis).

Such an analysis points both to the need to consider individual 'choice' and 'constraints' as well as to the influences of macro-scale economic and political processes.

There is, however, considerable debate about the degree to which the physical characteristics of a neighbourhood have an impact on the social outcomes of its inhabitants. It has been argued for example, that 'disadvantaged individuals in an isolated area will form one set of social relations, while disadvantaged individuals in a well-connected area may form another' (Lupton, 2003, p. 5; see also Spicker, 2001 and Vaughan and Geddes, 2009 for empirical research into the existence of 'poor areas'). Recent research points to explanations for these 'neighbourhood effects': Galster et al. (2008), for example, argue that several mechanisms existing at the local neighbourhood level affect social outcomes, including negative role models, peer effects and effects to do with a lack of access to information networks.

The notion and understanding of segregation has progressively evolved and it is increasingly being considered as a complex and multi-dimensional process (Maloutas, 2004, p. 4). In some instances, apparently new theories stem from arguments debated in previous decades. For instance, the 1960s-1970s discussion of la mixité sociale and mixed neighbourhood policies has been recently revived as part of the drive towards mixed-use and integrated housing policies in Western Europe (Cheshire, 2009).

In this sense, all theories can be regarded both as a result and a cause of 'dialectical progressions', simultaneous to events and theories, where the meaning of 'new' is thus historically and contextually relative. Not only does the concept and understanding of segregation require constant rethinking to come to terms with new realities, segregation as a theoretical framework, as well as an operational framework, will also continue to carry that intrinsic paradox, typical of multi-dimensional and multi-disciplinary concepts, whereby the inherent complexity of segregation as a phenomenon makes it difficult to explain by means of one theory alone (Van Kempen, 2002, p. 46). Although the debate surrounding the measurement and labelling of the phenomenon continues, as evidenced in recent exchanges in the academic literature (Johnston et al., 2005; Simpson, 2005; Peach, 2009), there is clearly still a gap in the evidence on the degree to which spatial context has an impact on social outcomes. The challenge of defining what we mean by segregation must be taken back to first principles, to the inherent uncertainty in defining differences between human groups (Mateos, in this issue). 


\section{Beyond the Ghetto}

Areas labelled as 'ghettos' are frequently simply residential clusters of homogenous groups, whose stigma of a lack of social integration with the rest of the city stems from a notion that dispersal of minorities is the only solution to the apparent problem.

Going back as far as sixteenth-century Venice, where Jews were restricted to living in an area known as 'Ghetto' (figure 1), it is clear that despite severe restrictions on movement and economic activities, the Jewish inhabitants were not entirely cut-off from society, as the word 'ghetto' now implies. Research shows that high rates of cultural interchange took place between the Jewish Ghetto inhabitants and Venetian society and beyond (Ruderman, 2010, esp. chapter 3: 'Knowledge Explosion'). On the same subject Sennett (1994) has pointed out the paradox that, despite the severe proscriptions on activity imposed on the Jewish inhabitants of the Venice Ghetto (and to a certain degree on other minority groups in the city), the fact of their seclusion allowed for a limited amount of 'self-determination', an enrichment of community life and indeed a degree of protection from the Christian mobs during Lent. Similarly, Sibley (1992, p. 121) has suggested that clustering is also sometimes a benefit beyond maintenance of home culture: there may be an advantage to minority clusters 'to remain hidden, out of sight of the dominant society...' since they are less likely to be rejected if the majority population is unaware of them. Clustering is viewed in this case as a protective device for oppressed minorities.

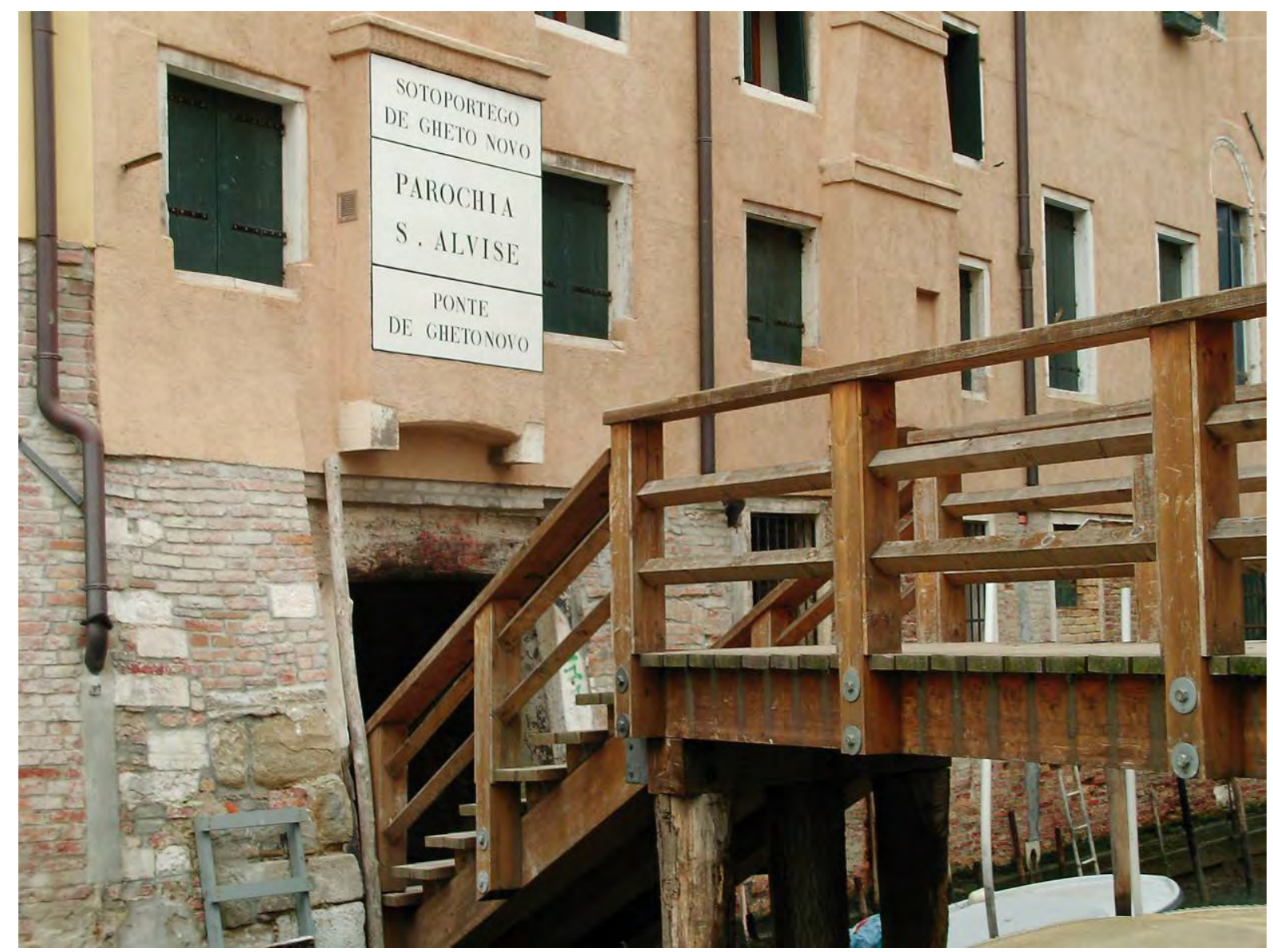

Figure 1. The Venice Ghetto walls - protective or controlling device? (Photo: by courtesy of Kayvan Karimi) 
Many studies of residential patterns make an unthinking equation between spatial segregation and social segregation; while segregation is frequently seen as primarily a problem of the spatial isolation of the poor. Along similar lines, ethnic concentration has recurrently been considered as the spatial representation of marginalization, separateness and oppression (Wilson, 1987), while drawing from the argument that living in socially or ethnically homogeneous neighbourhoods has primarily negative effects in terms of aspiration, opportunity, discrimination, stigmatization and crime, and hinders processes of upward mobility (Massey and Denton, 1993).

The emerging metaphors of the 'dual city', 'divided city' or 'hour-glass society' (North, 2004) can be linked with a dualist conception of urban order, where the social and spatial dimensions of the processes of polarization, inequality and segregation are considered interchangeable. Particularly in post-Fordist societies, the idea that spatial distance between different social groups leads to their segregation has accentuated the negative perception of ethnic concentration. This is encapsulated in the notion of the 'underclass' (Wilson, 1987), or in the current argument about the existence of the 'hyperghetto' in the US (Wacquant, 2007). Both notions have been employed to legitimize policies and programmes of dispersal and mixing on both sides of the Atlantic. ${ }^{1}$ Arguably, a policy approach which sees an unwavering line of progression from immigration to integration ignores the complexity of individual patterns of social interaction and memberships of social groups: '... even in highly mixed neighbourhoods, one may only have contact within one's own group’ (Lindo, 2005, p. 10). Indeed, Musterd and Ostendorf (2009, p. 1529) maintain that 'it is unclear whether more contact between very different people does indeed result in higher levels of integration and increased individual opportunities'. Moreover, Galster et al. (2010) show that neighbourhood mixing policies require a more nuanced approach than simply housing people according to income, due to the varying and sometimes contradictory outcomes for such policies on different individuals.

Despite being widely contested, the argument that mixed neighbourhoods are a panacea for integration has continued to surface on the political and urban agenda since the 1960s. The perception is that mixed neighbourhoods lead to a more inclusive society; namely that the ideal city is one comprising a mosaic of affluent enclaves and socio-ethnically mixed neighbourhoods. The proposition that the mixed neighbourhood is the perfect solution for segregation continues to be widely used as a reference point of discussion, despite being superseded by more advanced urban debates, and a wealth of studies of the topic (Barou, 1997; Lindo, 2005). One reason for a lack of sophisticated analysis of urban segregation could be the limitations of analytic tools for analysing spatial concentrations of ethnic groups and this is an emerging critique in the literature (Dunn, 1998; Lupton, 2003).

There is growing evidence that dispersal programmes can be problematic (Wilson, 1987; Darcy, 2010) and critics of such programmes argue that they stem from a naïve assumption that greater mixing between poorer and more prosperous individuals will of itself lead to greater social mobility (Porter and Shaw, 2009); see above discussion on neighbourhood effects. Critics of dispersal programmes argue that they do not deal with the underlying 'structural causes of regional and city economic decline and poverty' (Musterd and Ostendorf, 2005, p. 2346). The common problem is seen to be that programmes of urban renewal do not account for the consequential shifts in social structure within and outside the affected areas, since the unforeseen consequence of urban renewal programmes can be to trigger a gentrification process that prices poorer people out of a neighbourhood (Porter and Shaw, 2009; Arbaci and Malheiros, 2010). 
While there is now a significant amount of research which refutes the notion that residential segregation is inherently problematic (Simpson, 2004), it is also necessary to challenge the focus on segregation as a purely residential phenomenon. This belies the fact that it is in the public realm: 'the street, community centre, work, park, and other public spaces, [which] are more meaningful sites of ethnic segregation for people's everyday lives, especially for women and young people' (Phillips, 2007, p. 1147). Moreover, the need to understand the specific spatial context is frequently overlooked: life in a poor neighbourhood is different from one in a mixed-income neighbourhood and it is vital to consider this difference in order to understand everyday constraints on integration, such as access to work or the mixing of populations in the public realm.

Academics are nowadays more likely to shift between the scale of analysis from the macro - considering national welfare and housing regimes or citizenship (Musterd and Andersson, 2005; Arbaci, 2007) - to the city scale - considering socio-urban structures and governance (White, 2002); to the finest dimensions of the neighbourhood - including social and ethnic dynamics (Kesteltoot and Meert, 1999; Musterd and Ostendorf, 2005). These are leading to more nuanced discussions of policy, where evidence is brought to bear on whether the local or larger scale area is the dominant factor in social exclusion (Andersson and Musterd, 2010); and to more detailed analyses of the spatial impact of such policies (see Greene et al. and Murtagh, both in this issue). The renewed focus on the neighbourhood scale has also meant that the physical environment has become more prominent in the analysis of the mechanisms of differentiation (Friedrichs et al., 2005).

Despite the developments in academic work, public policy continues to be hindered by a lack of clear definitions of terms such as 'community' and 'segregation'. A review of these challenges by Strier (2009) argues that this lies at the heart of the difficulties in constructing policies in this arena. While the policy agenda in the UK is now shifting away from concepts such as 'community cohesion' and 'multi-culturalism' towards notions of racial and economic equality of opportunity (Department for Communities and Local Government, 2009), a lack of clear definitions of terms as well as a lack of understanding of the ultimate aims of such policies continues to hamper debate. For example, if spatial segregation is bad, where is the evidence that integration - or residential mixing - is necessarily good? The lack of clarity regarding the relationship between immigrant settlement patterns and social outcomes in the contemporary city demonstrates the urgent need for innovative thinking in this area, since there is a dichotomy surrounding research into the relationship between society and space. While the social sciences tend to lack an understanding of the independent contribution of the built environment to the way in which communities change over time, the spatial sciences lack an understanding of the political and cultural dynamics underpinning statistical measures of segregation.

Most vitally, there is a need to understand spatial configuration - the complex interactions between the parts and whole of the city - in order to understand the phenomenon of segregation. The reason this matters is that the way in which urban spaces both acquire social meaning and have social consequences comes out of how they form part of the city's layout (Hillier and Vaughan, 2007).

\section{The Role of Spatial Configuration in Social Segregation}

An understanding of how the public realm, shaped by urban form, can create the potential for encounters and co-presence between different types of social groups, is essential to achieve a more nuanced understanding of cities, migration and settlement patterns, since only thus is 
progress made from the simplistic assumption that clustering equates with ghettoization. As pointed out in 'The architecture of community' (Hanson and Hillier, 1987), individuals are simultaneously members of two different kinds of social grouping: spatial groups - which occur 'by virtue of proximity' and transpatial groupings, which 'unite people independently of space' (such as members of a church or club).

In complex societies containing many and varied communities, public space has a different role to play than a straightforward correspondence with the society which it contains. Rather, the urban environment can be structured so as to enable the encounters between different social groups, both spatial and transpatial (Vaughan, 2007). Social groups have a range of principles of solidarity, encoded into 'different daily routines and practices that lead to different modes of spatial co-presence ... these 'code' differences [are] realised in patterns of local encounter' (Hanson, 2000, p. 115). Community membership can shift in time and space, so that an individual can express different solidarities throughout the course of a day or week:

I effectively have integrated. I've gone to predominantly white schools, I work in a white firm, and I can live anywhere I want. [Yet] it really is psychologically soothing for me [when one goes home to] Harlem, when you are in your own community ... basking in [your] own culture.

As this quote from Varady (2005, p. xiv) shows, the spatial dimensions of 'community' vary and overlap. 'Community' can have both a highly spatialized as well as a highly transpatial formation. Instead of the constant search for a static definition of community and rather than the use of volatile concepts such as 'multiculturalism' and 'community cohesion', it is culture itself and its means of spatial and social manifestation that need to be properly understood, as stated by Werbner (2005). Any attempts to enforce cohesion on supposedly ghettoized communities is likely to do harm in that, by definition, it ignores the permeability of the spatial form as well as the fluidity of the social structure of minority groups.

Many urban theorists have pointed out that the pattern of everyday life - whether it is the chance encounters outside the front door, or the conversation while the children are at play in the local square, or the chat at the city-centre snack bar at lunchtime - are the raw material of society. As shown by Hillier and Hanson (1984), in their seminal The Social Logic of Space:

[the] man-made physical world ... constitutes (not merely represents) a form of order in itself: one which is created for social purposes, whether by design or accumulatively, and through which society is both constrained and recognisable. It must be the first task of theory to describe space as such a system. (Ibid., p. 9)

Arguably the street is more important for newly arrived minority groups than for others. Roberts (1973, p. 43), in his history of early twentieth-century Salford's 'Classic Slum', maintains that the street acted as a mechanism for 'storing and redistributing information that could be important economically to themselves and their neighbours'. Research into historical cases of supposed 'ghettoization' have shown that there is a much more complex picture than the simplistic notion of the immigrant residential quarter cutting its inhabitants off from society. In fact, depending on the location and the way in which the street network is utilized, clustering can enable the intensification of communal activity, socialization, networking and self-support. Analysis has shown that clustering of immigrants during the initial stages of settlement - and sometimes beyond the first generation - is part of a natural process of acculturation and integration (Vaughan, 2007). The research suggests that for immigrants, settlement in locations which enable economic activity is a necessary step in the 
immigrant process (Vaughan and Penn, 2006), and often entrepreneurship in ethnically concentrated neighbourhoods not only results in processes of 'mixed-embeddedness' and economic integration, but strengthens social networks and reciprocity, and enhances electoral power (Body-Gendrot et al., 2000; Kesteltoot and Meert, 1999; Vaughan, 2005). It should, however, also be pointed out that there is evidence that longer term minority clustering can have a negative effect: impeding social mobility (Galster et al., 2008), limiting access to work (Musterd et al., 2008), enabling criminal behaviour (Ceccato and Oberwittler, 2008), or hampering school achievement (Sykes and Kuyper, 2009).

Another issue frequently overlooked in segregation studies is that a group can be integrated in one sphere, such as through economic exchange in the marketplace, whilst maintaining strong internal social ties, as evidenced by a study of the nineteenth-century Jewish settlement of Manchester and Leeds (Vaughan, 2005). A similarly important distinction between people at different stages of their lives is indicated by (Phillips, 2006, p. 35), who shows that while for some British Muslims, clustering by choice in vital: 'Everything is here, our culture, our shops, mosque ... and the best thing about this area [Manningham]: no racism'. Others, particularly the children of Muslim immigrants, prefer to move away from community spaces. The move is:

symbolically important, especially for some younger women. The newly acquired spaces enable them to occupy a social, cultural, and spatial position on the margins of the community, which affords some freedom from perceived social strictures and conventions ... [but still] not too far away from the family home. (Ibid.)

Other research has found that public space plays an important role in bringing disparate groups together, although some sources state that only meaningful everyday contact (such as in the classroom or the workplace) can serve this purpose (Amin, 2002; Hewstone et al., 2005; Valentine, 2008).

The phenomenon where groups traditionally perceived to be politically divided integrate when relocated in another sphere is another theme that emerges in several studies. London in particular frequently features as a place where for ethnic groups such as Pakistanis and Indians, or Greek and Turkish Cypriots, residential and economic clustering exist and 'cordial relations' are manifested between diasporic communities that were in a situation of hostility in their countries of origin (Robins and Aksoy, 2001; Thomas, 2010). Equally, the emergence of London and other cities as places of 'super-diversity', means that groups that are outwardly perceived as uniform, mask an essential range of differences that is ignored at the researcher - and the policy-maker's - peril. Ceri Peach's analysis of the 'South Asian community' demonstrates this in particular, where he has shown that housing needs and economic trajectories are profoundly different for the East African, Pakistani and Bangladeshi people included within this group (Peach, 1998). Another interesting outcome of super-diversity is that groups of the same religious background can find themselves having to reflect on and adapt their own practices and beliefs, once they encounter the 'multiplicity of traditions of faith within each religious group due to the variety of countries of origin' in such places (Vertovec, 2006, p. 12). This was also the case in seventeenth-century Venice, where Ashkenazi and Sephardi Jews, who came from diverging cultural, linguistic and ritual traditions, were brought together in the 'same dense, bounded space' where a mutual identity was subsequently forged (Sennett, 1994, p. 244). Clearly, identifying immigrants and minorities purely by religion is highly reductive when attempting to understand segregation in such contexts. 
The aim of this special issue in general - and this paper in particular - is therefore to emphasize the complexity of segregation as a phenomenon that takes place in space and time. Understanding that society leaves traces on its surroundings and that those surroundings have in turn an influence on how society is structured, is at the heart of this notion, whereby it has been shown how it is the emergent structure of space, rather than the formal geometric definition of any particular physical object or array of objects, that explains its fundamentally social nature (Griffiths, et al., 2010; Hillier, 1999).

Although segregation is traditionally seen to be a residentially placed problem of poverty and ethnic exclusion, it should also be broadened to encompass the broader ranges of inequalities in the urban realm. For instance, the issue of school segregation is an increasing focus of debate as a phenomenon which might constrain socio-economic opportunities (Lupton and Tunstall, 2008). The definition of schools as 'micro-public' spaces, means that an absence of educational integration can play a key role in shaping patterns of division (Amin, 2002) and this is very much the focus of debate in cities with a longstanding history of ethnic division, such as Belfast or Nicosia. Similarly, whereas in the past cities such as London created an environment where rich and poor were close together, but marginally separated at street scale, a growing phenomenon across the world is the creation of gated residential areas (one hesitates to term these 'communities'), whose contact with surrounding streets is minimal, and impact is maximal, due to their interrupting the flow of movement in the area. This 'privatization of the public sphere' (Glasze et al., 2006) is arguably as problematic as is the supposed 'hypersegregation' so often cited in discussions of urban problems. Indeed there is a growing consensus in the Latin American segregation literature that, although the growth of gated communities might be reducing 'apparent' segregation, through diminishing numbers according to the standard indices which measure population mixing, these hide the encapsulation of the affluent amongst the poor at very fine spatial scales. The scale of operation of segregation then is central to understanding what it really means in these contexts. ${ }^{2}$

Segregation is not only a broader subject conceptually; it also shifts in its focus from location to location. In the UK and Europe the focus tends to be on social and ethnic difference, whilst in Latin America it is predominantly an issue of class; in Australia much of the discourse is around new versus old migrants (see paper by Wise in this issue); and in Belfast and Nicosia religious divide frequently masks class differences (see paper by Charalambous and Hadjichristos in this issue) just as much as in Israel, where the focus is on religious as well as ethnic differences (see paper by Omer in this issue). The shift changes again in the US, where the discourse has traditionally been first and foremost about race (although arguably masking a class problem too - see Varady, 2005).

Different disciplines approach the problem at different scales too: both in terms of geographic scale, and in terms of scale of discussion, since the scale of interest is often determined by the discipline. Thus, some discussions in the sociological literature focus on the home or places of worship (Eade and Garbin, 2002), the spatial sciences commonly concentrate on identifying and mapping change at the neighbourhood scale (Johnston et al., 2002; Simpson, 2004) and the mathematical sciences have a predominant focus on measuring scale across wide areas of the city without necessarily taking account of real, lived space at all (Yizhaq, 2004). What is evident is that without a multi-scalar approach that takes account of the relationship between localized patterns of mutuality and division and wider-scale opportunities for movement across space and time, the ability to handle the social complexity of the subject is lost. Equally, without recognizing that a differing spatial context, such as the inner-city or the outer suburb, can have a profound impact on social division, the spatial complexity of the subject is also lost. Indeed, it has been suggested that a 'proper resolution' 
of these questions will require 'more elaborate research design, in which the macroscopic approach of aggregate statistical analysis [is] married with special microscopic studies designed to elucidate behavioural motivations and effects' (Carling, 2008, p. 558). It is hoped that this special issue will achieve the aim of addressing the complexity of segregation as a social-spatial issue, demonstrating that the discourse around segregation has to get beyond the ghetto: both physically and theoretically.

\section{NOTES}

1. For example, the HOPE VI and MTO public housing projects in the USA (Imbroscio, 2008); Contracts de Ville in France (Simon, 2002); Urban Revitalisation Policy and Housing Differentiation Programmes in the Netherlands, (Kruythoff, 2003); and the mixed tenure policy under the Sustainable Communities agenda in the UK (Lupton and Tunstall, 2008; Cheshire, 2009).

2. We are grateful to Pablo Mateos for pointing this out. See also Brillembourg et al. (2005).

\section{REFERENCES}

Amin, A. (2002) Ethnicity and the multicultural city: living with diversity. Environment and Planning A, 34, pp. 959-980.

Andersson, R. and Musterd, S. (2010) What scale matters? Exploring the relationships between individuals' social position, neighbourhood context and the scale of the neighbourhood. Geografiska Annaler: Series B, Human Geography, 92, pp. 23-43.

Arbaci, S. and Malheiros, J. (2010) De-segregation, peripheralisation and the social exclusion of immigrants: Southern European cities in the 1990s. Journal of Ethnic and Migration Studies, 36, pp. 227 -255.

Barou, J. and Baillergeau, E. (1997) Les politiques d’integration des États européens vues à travers quelques experiences sectorielles. Revue Française des Affaires Sociales, no. 2, pp. 167-184.

Body-Gendrot, S., Martiniello, M. and Centre for Research in Ethnic Relations (2000) Minorities in European Cities: The Dynamics of Social Integration and Social Exclusion at the Neighbourhood Level. Basingstoke: Macmillan.

Brillembourg, A., Feireiss, K. and Klumpner, H. (eds.) (2005) Informal City: Caracas Case. Munich: Prestel.

Carling, A. (2008) The curious case of the mis-claimed myth claims: ethnic segregation, polarisation and the future of Bradford. Urban Studies, 45, pp. 553-589.

Ceccato, V. and Oberwittler, D. (2008) Comparing spatial patterns of robbery: Evidence from a Western and an Eastern European city. Cities, 25, pp. 185-196.

Cheshire, P. (2009) Policies for mixed communities: faith-based displacement activity? International Regional Science Review, 32, pp. 343-375.

Darcy, M. (2010) De-concentration of disadvantage and mixed income housing: a critical discourse approach. Housing, Theory and Society, 27, pp. 1-22.

Department for Communities and Local Government (2009) Tackling Race Inequalities: A Discussion Document. London: DCLG.

Dunn, K. (1998) Rethinking ethnic concentration: the case of Cabramatta, Sydney. Urban Studies, 35, pp. 503527.

Eade, J. and Garbin, D. (2002) Changing narratives of violence, struggle and resistance: Bangladeshis and the competition for resources in the global city. Oxford Development Studies, 30, pp. 137-149.

Friedrichs, J., Galster, G. and Musterd, S. (2005) Life in Poverty Neighbourhoods: European and American Perspectives. London: Routledge.

Galster, G., Andersson, R., Musterd, S. and Kauppinen, T.M. (2008) Does neighborhood income mix affect earnings of adults? New evidence from Sweden. Journal of Urban Economics, 63, pp. 858-870.

Galster, G., Andersson, R. and Musterd, S. (2010) Who is affected by neighbourhood income mix? Gender, age, family, employment and income differences. Urban Studies, 47, pp. 2915-2944.

Glasze, G., Webster, C. and Frantz, K. (2006) Private Cities: Global and Local Perspectives. London: Routledge.

Griffiths, S., Jones, C.E., Vaughan, L. and Haklay, M. (2010) The persistence of suburban centres in Greater London: combining Conzenian and space syntax approaches. Urban Morphology, 14, pp. 85-99. 
Hanson, J. (2000) Urban transformations: a history of design ideas. Urban Design International, 5, pp. 97-122.

Hanson, J. and Hillier, B. (1987) The architecture of community: some new proposals on the social consequences of architectural and planning decisions. Architecture et Comportement/Architecture and Behaviour, 3, pp. 251-273.

Hewstone, M., Cairns, E., Voci, A., Paolini, S., Mclernon, F., Crisp, R. and Niens, U. (2005) Intergroup contact in a divided society: challenging segregation in Northern Ireland, in Abrams, D., Marques, J.M. and Hogg, M. A. (eds.) The Social Psychology of Inclusion and Exclusion. Philadelphia, PA: Psychology Press.

Hillier, B. (1999) Space as a paradigm for describing emergent structure in strongly relational systems, in Hollanda, F., Amorim, L. and Dufaux, F. (eds.) Second International Space Syntax Symposium. Brasilia.

Hillier, B. and Hanson, J. (1984) The Social Logic of Space. Cambridge: Cambridge University Press.

Hillier, B. and Vaughan, L. (2007) The city as one thing. Progress in Planning (special issue on The Syntax of Segregation, edited by Laura Vaughan), 67, pp. 205-230.

Imbroscio, D. (2008) ‘[U]nited and actuated by some common impulse of passion’: challenging the dispersal consensus in American housing policy research. Journal of Urban Affairs, 30, pp. 111-130.

Johnston, R.J., Forrest, J. and Poulsen, M. (2002) Are there ethnic enclaves/ghettos in English cities? Urban Studies, 39, pp. 591-618.

Johnston, R.J., Poulsen, M. and Forrest, J. (2005) On the measurement and meaning of residential segregation: a reesponse to Simpson. Urban Studies, 42, pp. 1221-1227.

Kesteltoot, C. and Meert, H. (1999) Informal spaces: the geography of informal economic activities in Brussels. International Journal of Urban and Regional Research, 23, pp. 232-251.

Kruythoff, H. (2003) Dutch urban restructuring policy in action against socio-spatial segregation: sense or nonsense? European Journal of Housing Policy, 3, pp. 193-216.

Lindo, F. (2005) The concept of integration: theoretical concerns and practical meaning, in Fonseca, L. and Malheiros, J. (eds.) Social Integration and Mobility: Education, Housing and Health. Lisbon: Estudos para o Planeamento Regional e Urbano, CEG Universidade de Lisboa.

Lupton, R. (2003) ‘Neighbourhood Effects’: Can We Measure Them and Does It Matter? CASE paper 73. Centre for Analysis of Social Exclusion, London School of Economics and Political Science.

Lupton, R. and Tunstall, R. (2008) Neighbourhood regeneration through mixed communities: a 'social justice dilemma'? Journal of Education Policy, 23, pp. 105-117.

Maloutas, T. (2004) Editorial: urban segregation and the European context. The Greek Review of Social Research, 113, pp. 3-24.

Marcuse, P. and Van Kempen, R. (2002) Of States and Cities: The Partitioning of Urban Space. Oxford: Oxford University Press.

Massey, D. and Denton, R. (1993) American Apartheid: Segregation and the Making of the Underclass, Cambridge, MA: Harvard University Press.

Musterd, S. and Andersson, R. (2005) Housing mix, social mix, and social opportunities. Urban Affairs Review, 40, pp. 761-790.

Musterd, S., Andersson, R., Galster, G. and Kauppinen, T. M. (2008) Are immigrants' earnings influenced by the characteristics of their neighbours? Environment and Planning A, 40, pp. 785-805.

Musterd, R. and Ostendorf, W. (2005) Social exclusion, segregation and neighbourhood effects, in Kazepov, Y. (ed.) Cities of Europe. Changing Contexts, Local Arrangements, and the Challenge to Urban Cohesion. Oxford: Blackwell.

Musterd, S. and Ostendorf, W. (2009) Residential segregation and integration in the Netherlands. Journal of Ethnic and Migration Studies, 35, pp. 1515-1532.

North, P. (2004) Book review: Unequal City: London in the Global Arena: Chris Hamnett.. Cities, 21, pp. 465466.

Park, R.E. (1926) The urban community as a spatial pattern and a moral order, in Burgess, E. W. (ed.) The Urban Community. reprinted in Peach, C. (ed) (1975) Urban Social Segregation. Chicago, IL: University of Chicago Press.

Peach, C. (1998) South Asian and Caribbean ethnic minority housing choice in Britain. Urban Studies, 35, pp. $1657-1680$.

Peach, C. (2005) The ghetto and the ethnic enclave., in Varady, D.P. (ed.) Desegregating the City: Ghettos, Enclaves and Inequality. Albany, NY: State University of New York Press.

Peach, C. (2009) Slippery segregation: discovering or manufacturing ghettos? Journal of Ethnic and Migration Studies, 35, pp. 1381-1395.

Phillips, D. (2006) Parallel lives? Challenging discourses of British Muslim self-segregation. Environment and Planning D: Society and Space, 24, pp. 25-40.

Phillips, D. (2007) Ethnic and racial segregation: a critical perspective. Geography Compass, 1, pp. 1138-1159.

Phillips, D., Davis, C. and Ratcliffe, P. (2007) British Asian narratives of urban space. Transactions of the Institute of British Geographers, 32, pp. 217-234. 
Porter, L. and Shaw, K. (eds.) (2009) Whose Urban Renaissance? An International Comparison of Urban Regeneration Strategies. London: Routledge.

Roberts, R. (1973) The Classic Slum: Salford Life in the first Quarter of the Century. Harmondsworth: Penguin.

Robins, K. and Aksoy, A. (2001) From spaces of identity to mental spaces: lessons from Turkish-Cypriot cultural experience in Britain. Journal of Ethnic and Migration Studies, 27, pp. 685-711.

Ruderman, D. (2010). Early Modern Jewry: a new cultural history. Princeton and Oxford: Princeton University Press.

Sennett, R. (1994) Flesh and Stone - the Body and the City in Western Civilization. New York: W.W. Norton.

Sibley, D. (1992) Outsiders in society and space, in Anderson, K. and Gale, F. (eds.) Inventing Places: Studies in Cultural Geography. New York: Wiley.

Simon, P. (2002) When de-segregation produces stigmatisation: ethnic minorities and urban policies in France, in Martiniello, M. and Piquard, B. (eds.) Diversity in the City. Bilbao: University of Deusto.

Simpson, L. (2004) Statistics of racial segregation: measures, evidence and policy. Urban Studies, 41, pp. 661681.

Simpson, L. (2005) On the measurement and meaning of residential segregation: a reply to Johnston, Poulsen and Forrest. Urban Studies, 42, pp. 1229-1230.

Spicker, P. (2001) Poor areas and the 'ecological fallacy'. Radical Statistics, no. 76, pp. 38-79.

Strier, R. (2009) Community anti-poverty strategies: a conceptual framework for a critical discussion. British Journal of Social Work, 39, pp. 1063-1081.

Sykes, B. and Kuyper, H. (2009) Neighbourhood effects on youth educational achievement in the Netherlands: can effects be identified and do they vary by student background characteristics? Environment and Planning A, 41, pp. 2417-2436.

Thomas, R. (2010) 'South Asian’ Diasporas in London: Clustering and Cultural Exchange. MSc dissertation. London: Bartlett School of Graduate Studies, University College London.

Valentine, G. (2008) Living with difference: reflections on geographies of encounter. Progress in Human Geography, 32, pp. 323-337.

Van Kempen, R. (2002) The academic formulations: explanations for the partitioned city, in Marcuse, P. and Van Kempen, R. (eds.) Of States and Cities: The Partitioning of Urban Space. Oxford: Oxford University Press.

Varady, D. P. (ed.) (2005) Desegregating the City: Ghettos, Enclaves and Inequality. Albany, NY: State University of New York Press.

Vaughan, L. (2005) The relationship between physical segregation and social marginalisation in the urban environment. World Architecture, no. 185, pp. 88-96.

Vaughan, L. (ed.) (2007) The Spatial Syntax of Urban Segregation, Oxford: Elsevier.

Vaughan, L. and Geddes, I. (2009) Urban form and deprivation: a contemporary proxy for Charles Booth’s analysis of poverty. Radical Statistics, no. 99, pp. 46-73.

Vaughan, L. and Penn, A. (2006) Jewish immigrant settlement patterns in Manchester and Leeds 1881. Urban Studies, 43, pp. 653-671.

Vertovec, S. (2006) The Emergence of Super-Diversity in Britain. Oxford: Centre of Migration, Policy and Society, University of Oxford.

Wacquant, L. (2007) Urban Outcasts: A Comparative Sociology of Advanced Marginality. Cambridge: Polity.

Werbner, P. (2005) The translocation of culture: 'community cohesion' and the force of multiculturalism in history. The Sociological Review, 53, pp. 745-768.

White, P. (2002) Migration and Mediterranean urban societies: policy contexts and concerns, in Fonseca, L. and Luso-American Development Foundation (eds.) Immigration and Places in Mediterranean Metropolises. Lisbon: Fundação Luso-Americana para o Desenvolvimento.

Wilson, W. (1987) The Truly Disadvantaged: The Inner City, the Underclass and Public Policy. Chicago, IL: University of Chicago Press.

Yizhaq, H. (2004) A mathematical model of segregation patterns in residential neighbourhoods. Environment and Planning A, 36, pp. 149-172.

\section{ACKNOWLEDGEMENTS}

We would like to thank the participants of the 'Beyond the Ghetto' workshop which took place in May 2010 with funding from the UCL Grand Challenge: Sustainable Cities. In particular, the responses from the three invited experts: Professor Pnina Werbner (Social Anthropology, Keele), Professor Ceri Peach (Social Geography, Oxford) and Professor Ludi Simpson (Population Studies, Manchester) were essential to developing the arguments in this paper. The paper should not however be seen to necessarily reflect the views of the workshop's participants. 